\title{
Analysis of the Impact of Education Poverty Alleviation on Economic Growth in Shaanxi Province
}

\author{
Yaru Liu \\ Shaanxi Institute of International Trade \& Commerce, Xi’an, Shaanxi Province, 712046, China
}

Keywords: Shaanxi Province, Education Poverty Alleviation, Economic Growth, Population Comprehensive Quality

\begin{abstract}
At present, the level of economic development in poverty-stricken areas in our country is low, and at the same time the material development is relatively backward. It is hard to achieve people's rich living standards and spiritual and cultural standards. In order to change this phenomenon, we must start from the education poverty alleviation, improve the basic quality of the population in poor areas from education, and at the same time we must realize the economic development of the poor through education and poverty alleviation. To develop education is fundamental to changing the current situation in impoverished areas. Therefore, if we want to improve the productivity of impoverished areas, we must start from changing the mode of education. Based on the situation of poverty alleviation education in poverty-stricken areas in Shaanxi Province, this paper studies the theory of poverty and poverty alleviation education, and uses the research methods of dialectical analysis, empirical research and literature data to achieve the goal of poverty alleviation education. At the same time, it analyzes and summarizes the promotion effect of poverty alleviation education in Shaanxi Province on economic development, concludes that the province has made a very effective attempt in poverty alleviation education and finally has a good deterrent effect on the poverty situation, Households have been given the opportunity to get out of poverty.
\end{abstract}

\section{Introduction}

Poverty is one of the three major problems currently facing and must be solved in the world (ie pollution, population and poverty). ${ }^{1}$ At present, the vast majority of the poor in China are mainly distributed in the rural areas in the western region, and have gradually moved westwards, increasing the density of the poor in the west. ${ }^{2}$ In order to solve the problem of poverty in the western region, the state and the government have adopted a series of development policies and measures to help alleviate poverty: firstly, organically combine economic growth with related poverty alleviation programs; secondly, take development and poverty-based poverty reduction projects as the center, Regional self-"blood" function; the final implementation of regional positioning to poor villages as poverty alleviation and development of the smallest unit, which also formed the characteristics of China's current anti-poverty policy. ${ }^{3}$ The most important thing in poverty alleviation work is to give great support to education in the western region and to develop human resources.

At present, the level of economic development in poverty-stricken areas in our country is low, and at the same time the material development is relatively backward. It is hard to achieve people's rich living standards and spiritual and cultural standards. ${ }^{4}$ In order to change this phenomenon, we must start from the education poverty alleviation, improve the basic quality of the population in poor areas from education, and at the same time we must realize the economic development of the poor through education and poverty alleviation. To develop education is fundamental to changing the current situation in impoverished areas. ${ }^{5}$ Therefore, if we want to improve the productivity of impoverished areas, we must start from changing the mode of education. Based on the situation of poverty alleviation education in poverty-stricken areas in Shaanxi Province, this paper studies the theory of poverty and poverty alleviation education, and uses the research methods of dialectical analysis, empirical research and literature data to achieve the goal of poverty alleviation education. 


\section{Analysis of Present Situation of Education Poverty Alleviation in Shaanxi Province}

On the connotation of poverty alleviation and development, China has gradually realized the function of education in alleviating poverty and the role of education in economic development in poor areas has become the consensus of the community. ${ }^{6}$ To this end, Chinese scholars have conducted in-depth studies on poverty alleviation education and have achieved great success. Lin Qidong emphasized that education has the anti-poverty function and should be integrated into the poverty alleviation system. In the modern society, Professor Yan Wan-yue believes that the root cause of poverty in the region lies in the lack of knowledge and abilities, and the most important function of education in poverty alleviation. ${ }^{7}$ It not only can increase the population's labor skills and experience in impoverished areas, but also enable people to grasp the ability to get rid of poverty and prosperity, the long-term stability brings great benefits (Figure 1). At the same time, some scholars study the poverty alleviation in education from the perspective of economics. Zhang Hong, a PhD student from Lanzhou University, conducted an economic analysis on the participatory poverty alleviation model in Ma'an Village, Gansu Province. In his survey, he learned about the special ecological and economic conditions in different types of rural areas. Conditions, and summarizes some of the laws in poverty alleviation and education in education.

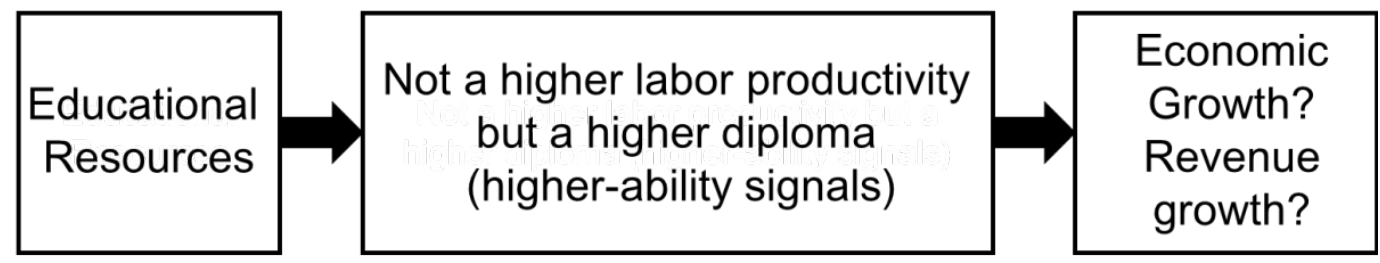

Figure 1.Filter assumptions or diploma notes theoretical diagram.

Education Poverty Alleviation is an effective investment, and the investment in education in poor areas is more conducive to increasing the awareness of the underprivileged people and promoting the economic development in poor areas. To lift the population in poverty-stricken areas out of poverty ultimately depends on their ability to shake off poverty and become rich. Education poverty alleviation is different from material-level poverty alleviation activities. It is more a process of continuously changing the concept of backwardness of the poor and only enhancing the ability of the poor to become wealthy. Although investment in education also requires some investment, poverty alleviation through education is an important measure to help the poor in poverty-stricken areas.

\section{The Impact of Education Poverty Alleviation on Economic Development in Shaanxi Province}

\section{Poverty Alleviation by Education Raise the Comprehensive Qualities of the Poor}

Education plays an important role in promoting economic development. It can not only change the concept of the poor but also bring about some benefits to poor areas. Since the reform and opening up, some poor people have been further educated through poverty alleviation through education so as to gain some knowledge and skills and achieve poverty alleviation and prosperity. Some poor people who go out to work first learn the educational knowledge in the city and become able to get out of poverty and become rich in poor areas. This shows that poverty alleviation through education can be practically feasible for alleviating poverty and getting rich in poverty-stricken areas. Education Poverty Alleviation Poverty Alleviation from the root causes can be achieved by changing the quality of the population in poor areas. The famous American sociologist Ingalls once pointed out: "Human modernization is an indispensable factor in the country's modernization. It is not a by-product of the end of the modernization process, but a prerequisite for the long-term development and success of the modern system and economic dependence. Conditions. "Education, however, is the primary and direct factor that has made poverty-stricken areas out of poverty. Poverty alleviation through education can change the 
backwardness of the poor, increase the income of the poor and increase the employment opportunities for the poor (Table 1). At the same time, the concept of the poor population is more adapted to the needs of the development of modern society. Therefore, education poverty alleviation has produced some benefits in poor areas.

Table1.Ankang poor population accounts for the proportion of registered population.

\begin{tabular}{|c|c|c|c|c|c|}
\hline Time (year) & 2006 & 2007 & 2008 & 2009 & 2010 \\
\hline Poverty as a percentage of total population (\%) & 56.33 & 48.25 & 48 & 36.52 & 38.12 \\
\hline
\end{tabular}

\section{Poverty Alleviation in Education Has a Positive Impact on the Development of Poverty-Stricken Areas}

Poor people in poverty-stricken areas have a strong desire for education on the basis of actual poverty. It is only because of family poverty that it is impossible to make educational investments, to implement education pro-poor policies, to increase the gold content of education for poverty alleviation and to subsidize education inputs from poor areas from various sources so as to enable more poor people to receive education. Despite the long investment cycle of education, it can raise the overall cultural quality of poor areas. In the meantime, in the long run, education poverty alleviation can promote sustained and coordinated economic development in impoverished areas as well as maintaining social harmony and stability and alleviating various problems caused by population pressure. By education poverty alleviation has changed the concept of backwardness, scientific and cultural quality continues to improve, more conducive to improving the concept of poor people to protect the ecological environment, promote the overall development of the region and the popularization of science and technology, so as to completely change the mentality of the poor in poor areas (Table 2).

Table 2. The proportion of agricultural population among poor people in Ankang City.

\begin{tabular}{|c|c|c|}
\hline Time (year) & The number of poor households & Proportion of rural population in poverty (\%) \\
\hline 2006 & 36000 & 95 \\
\hline 2007 & 28663 & 87 \\
\hline 2008 & 27563 & 85 \\
\hline 2009 & 21003 & 62 \\
\hline 2010 & 23006 & 59 \\
\hline
\end{tabular}

\section{Poverty Alleviation in Education in Great Leap Forward in Socialist China}

The role of education in economic growth has been recognized by the international community. In the past poverty alleviation and development, the poverty alleviation methods were basically based on the material aspects. However, they lacked the emphasis on long-term poverty alleviation within the poor population in poverty-stricken areas. Therefore, poverty alleviation should be emphasized in poverty alleviation projects. Deng Xiaoping once told foreign reporters: "Socialist wealth belongs to the people and social enrichment is the common prosperity of all people." Education Poverty Alleviation is part of the prosperity of socialism. We should vigorously develop education and promote the optimal allocation of educational resources. To a certain extent, poverty is a lack of elements of production resources, making it impossible for people to rely on local resources for production to meet their needs. Poverty alleviation through education can enable 
people to master the labor skills to escape poverty and change the face of poverty (Figure 2). At the same time, poverty alleviation by education can also change the concept of backwardness in poverty-stricken areas. Gradually receiving education is an effective way to get out of poverty and education poverty alleviation is more targeted to the poor. As some impoverished regions have said, "re-education, No longer suffer from children, "which shows that people are gradually realizing the role of education in changing poverty. Education for Poverty Alleviation not only contributes to the healthy development of the entire society, but also helps economic coordination and sustainable development and is more conducive to alleviating various social problems brought about by the population pressure in poverty-stricken areas. Therefore, education poverty alleviation should become the strategic focus of poverty alleviation work in the entire society.

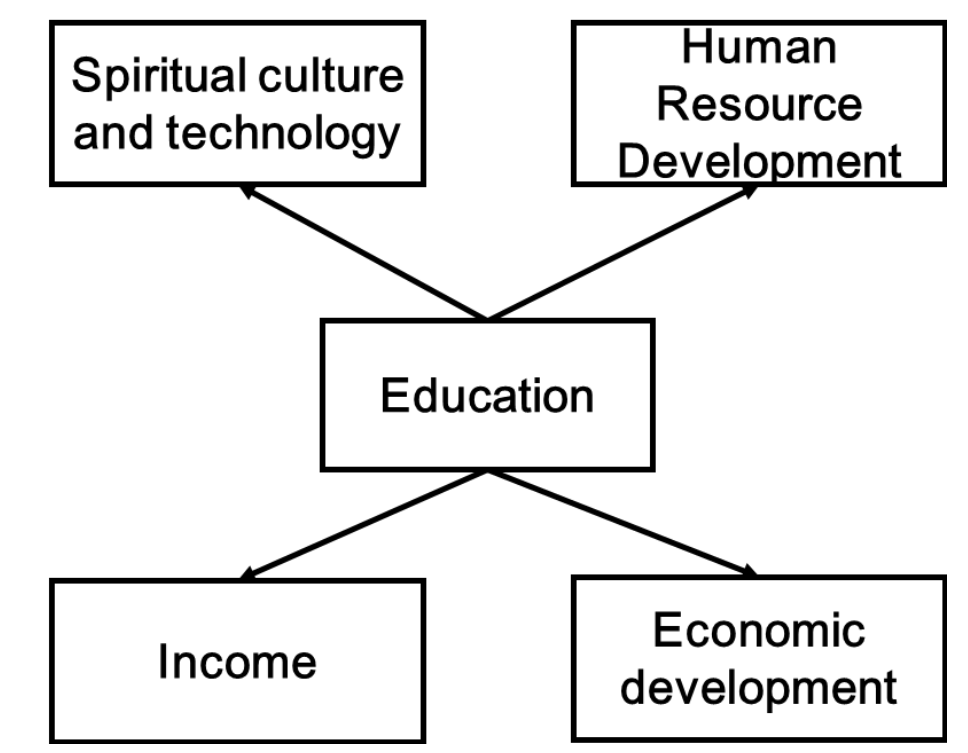

Figure 2. The Impact of Education on Poverty Alleviation.

\section{Summary}

Due to the influence of history, location, policy and other factors, the differences in the development of regional economy in our country have become increasingly obvious. The problem of poverty in Shaanxi will affect the realization of Shaanxi's economic construction and the goal of building an overall well-to-do society. It will also pose major challenges to the existing stability and unity in society. The shortage of human capital in the western region has seriously hampered the pace of getting rid of poverty in poor areas. As a result, a considerable part of the population in poverty-stricken areas of Shaanxi Province has not yet escaped poverty and has indirectly indirectly caused a considerable part of the population already deprived of poverty to return to poverty. However, the poor in Ankang City, the southernmost tip of Shaanxi Province Particularly prominent. Practice has proved that in order to fundamentally solve the problem of poverty, we must reform the strategy of alleviating poverty through material resources and implement the new poverty reduction strategy, that is, human capital strategy. In particular, we should pay attention to the role of human capital in the economic development in poor areas, the development of human capital is placed at the top of poverty alleviation and provides the most basic guarantee for material capital investment and the overall anti-poverty strategy. Education is the basic way to form human capital. The urgent need for human capital in economic development in poor areas needs to develop education in poor areas. Due to various factors, the development of education alone in poor areas is far from meeting the needs of economic development Therefore, we must take education as a new priority for poverty alleviation and give priority to development. At present, the most effective strategy to curb the spread of poverty and eliminate poverty and achieve sustainable development is to expand educational opportunities and improve the quality of education. We must uphold fairness and priority and vigorously develop poverty Regional education. 


\section{Acknowledgements}

This work was supported by Scientific Research Plan Projects of Shaanxi Province Education department: Research on poverty alleviation through education in Shaanxi

\section{References}

[1] Xiaowei Y, Jianmin G, Zhongliang Z, et al.. Assessing the Effects of the New Cooperative Medical Scheme on Alleviating the Health Payment-Induced Poverty in Shaanxi Province, China PLoS One. 2016; 11(7): e0157918.

[2] Anne D. G, Stephen P, Jane L, et al.. Natural capital and ecosystem services informing decisions: From promise to practice. Proc Natl Acad Sci. 2015: 7348-7355.

[3] Huijun L, Xiuhua H, Qunying X, et al.. Family Structure and Quality of Life of Elderly in Rural China: The Role of the New Rural Social Pension. J Aging Soc Policy. 2015: 123-138.

[4] Shixiong C, Binglin Z, Hui Y, et al.. Development and testing of a sustainable environmental restoration policy on eradicating the poverty trap in China's Changting County. Proc Natl Acad Sci. 2009: 10712-10716.

[5] Wei L, Yan-ju L, Zhifeng Y. Preliminary Strategic Environmental Assessment of the Great Western Development Strategy: Safeguarding Ecological Security for a New Western China. Environ Manage. 2012: 483-501.

[6] Kurt Sartorius, Benn Sartorius, Stephen Tollman, et al.. Rural Poverty Dynamics and Refugee Communities in South Africa: A Spatial-Temporal Model. Popul Space Place. 2013: 103-123.

[7] Cong L, Hua Z, Shuzhuo L, et al.. Impacts of conservation and human development policy across stakeholders and scales. Proc Natl Acad Sci. 2015: 7396-7401. 